International Journal of Engineering \& Technology, $7(2.13)(2018)$ 93-102
International Journal of Engineering \& Technology
Website: $w w w . s c i e n c e p u b c o . c o m / i n d e x . p h p / I J E T$
Research Paper

\title{
Study of surface layers obtained by copper ion implantation into a target of steel 30хгсн2a by auger Spectroscopy methods
}

\author{
Ovchinnikov V.V., Borovin Yu.M., Kurbatova I.A., Lukyanenko E.V., Uchevatkina N.V., Yakutina S.V. \\ Moscow Polytechnic University, Moscow \\ *Corresponding author E-mail: Ovchinnikov.V.V.2@gmail.com
}

\begin{abstract}
The relevance of the study due to the necessity of increase in the wear resistance of the tribological parts from steel 30XГСН2A through the copper ions implantation. The leading method for investigating this problem is the examination of the implanted layers of the target surface made of steel $30 \mathrm{XГСН} 2 \mathrm{~A}$ by means of auger spectroscopy making it possible to review the structure and distribution of the implanted ions comprehensively. The article presents the study results of copper, carbon and oxygen distribution regularities in the surface layers formed during copper implantation into the plates from steel 30ХГСН2A in the impulsive ions source. It has been established that in the process of copper implantation, a carbon layer with a thickness of $\sim 50 \mathrm{~nm}$ is formed on the surface. It is shown that in the intermediate layer (up to $100 \mathrm{~nm}$ ), the iron is partly in the oxidized condition. The possible mechanisms of the influence of surface layers structure formed in the result of copper implantation into the steel plate $30 \mathrm{XГCH} 2 \mathrm{~A}$ on their tribological characteristics are presented. The article materials are of practical value in developing the technology for wear resistance increase of the various parts of the revolution shape used in aircraft movable joints.
\end{abstract}

Keywords: Implantation; Auger Spectroscopy; Tribological Properties; Surface Layers; Carbon Steel; Wear; Copper Content.

\section{Introduction}

Traditional methods of surface treatment of construction materials to improve their physical, chemical, mechanical and other properties keeps developing intensively. The rapid development of technology specify increasing requirements to the realizable level of structural materials properties. Fundamentally, new prospects have opened the use of concentrated energy flows, including plasma flows, microwave radiation, beams of charged particles, in particular ion beams. Typically, the value of the ion energy used to treat the material surface is more than a few orders of magnitude exceeding the characteristic values of the interatomic interactions in solid bodies. Therefore, the processes of structure transformation and changing the structural-phase state of the target surface layers under treatment take place in conditions that are far from thermodynamic equilibrium, and in many cases this makes it possible to obtain surface layers and due to this the materials with unique properties. Ion implantation is the effective way to improve the surface properties of functional and structural materials [1-3]. The method of ion implantation has been developed in microelectronics where from the analysis of concentration profiles of impurity distribution in depths we determine the distinctive areas of the implantation doses at which p-n transitions, thickness of the modified layer and limiting concentration of implantable impurities should be expected to be formed [3].

The advantages of charged particles beams in comparison with other methods of energy deposition are obvious. They are the easy of control, the ability to disperse particles up to virtually any necessary energy, to receive high purity beams, high reproducibility and reliable controllability of ion processing parameters. The technologies associated with the influence of charged particles beams can significantly reduce the temperature of the processable product and significantly increase the processing efficiency. It should be noted that the financial and energy costs of ion-beam processing do not exceed those ones for traditional processing, and in some cases are much lower.

Ion beams are used not only in semiconductor technologies but also for the processing of construction materials. It should be noted that ion implantation of metallic materials differ fundamentally from the ion implantation of semiconductors. As was shown in the papers on ion implantation in metals [4-7], for purposeful change in the properties of metallic construction materials, the ion irradiation doses by several orders exceeding the doses required to change the semiconductor properties are required. For metallic materials, the significant changes in their physical, chemical and mechanical properties are observed in the concentrations of the alloying element embedded in surface layer during its implantation constituting units-tens of atomic percent.

The bombardment of the solid materials surface by the high-energy ions is accompanied by a number of physical phenomena or processes. Among them: the neutralization of the ion flying up to the surface and auger-electron emissions, the reflection of the part of bombarding ions and their energy, ion-electronic potential and kinetic emissions, ion-photon emissions, the ions implantation, the energy loss and the distribution of embedded atoms in depth of the solid body, radiation damages, diffusion and radiation-accelerated diffusion, ion spraying, blistering, peeling of the surface of some solid materials etc.

Implantation has found application in metallurgy $[1,2]$. This technique is now being introduced into technology of various parts that 
experience heavy surface loads during operation. The implantation of nitrogen ions into the surface of steel products prevents the formation of cracks, improves the corrosive and frictional properties of the structural materials used in medicine, including in the manufacture of the cutting instrument and in the aerospace industry for increasing the engine life.

The alloying of the thin surface layer of the target during ion implantation makes it useful for many engineering applications. However, there are several cases in which the influence of implanted ions on mechanical and physical-chemical properties is manifested at depths, significantly excessing the thickness of the surface layer under alloying, during ion implantation. Thus, the ion implantation at elevated temperatures, but below the temperatures at which mechanical properties are degraded, allows for a significant increase in the penetration depth of the alloying element $[8,9]$.

Papers [11-25] show the possibility of increasing the tribological properties of products from steel $30 \mathrm{XГCH} 2 \mathrm{~A}$ by implantation into their working surfaces the copper ions and the processing conditions that enhance the durability of these products have been determined. When testing samples for a linear wear it was determined that implantation of copper ions allows increasing the wear resistance by 2.5 times. The optimum irradiation dose is $10^{17} \mathrm{ion} / \mathrm{cm}^{2}$ The ion implantation technology has been proposed based on steel $30 \mathrm{XГCH} 2 \mathrm{~A}$ operating under high loads, sliding friction and wear conditions.

The authors $[11,26]$ draw attention to the fact that surface layers of steel 30ХГСН2A implanted with copper are enriched with carbon, and in this case, the carbon layer thickness increases with the in crease in the dose of implantation. Formation of the carbon layer they associate with hydrocarbons sorption from the 'dirty' vacuum. It should be noted that the formation of carbon and oxygen films was observed in [16] during aluminum implantation in titanium in the vacuum chamber with residual pressure of $4 \cdot 10^{-3} \mathrm{~Pa}$ equipped with a source of accelerated ions based on the continuous arc discharge.

It is known that oxide films on iron with protective properties are generated at room temperature. When the temperature rises, the speed of their formation increases dramatically. According to [27], which examined the kinetics of the oxide films formation on the iron during surface processing in glow discharge in atmosphere of residual gases, the speed of their formation significantly depend on the accelerating voltage.

It is obvious that the disclosure of mechanisms to increase the tribological properties of the products surfaces subjected to implantation is impossible without experimental data on the implantable component and impurities distribution in it the, as well as structural changes in the implanted layers depending on the implantation mode.

The purpose of this paper was the study of microstructure and elements distribution in the implanted layer of steel $30 \mathrm{XГCН} 2 \mathrm{~A}$ by copper ions based on auger spectroscopy techniques. The obtaining of such experimental data will make it possible to formulate a mechanism for increasing the tribological properties of steel $30 \mathrm{XГCH} 2 \mathrm{~A}$ after implantation. In turn, based on this mechanism, you will be able to assign parameters of implantation mode for purposeful change of the surface properties of the process able target.

\section{Materials and methods}

For copper ion implantation into steel $30 \mathrm{XГCН} 2 \mathrm{~A}$, the pulsed vacuum-arc ion source IGMI-50 with accelerating voltage of $30 \mathrm{kV}$ was used. The residual pressure in the vacuum chamber was $8 \times 10^{-}$ ${ }^{4} \mathrm{~Pa}$; the samples temperature during implantation process did not exceed $80^{\circ} \mathrm{C}$. The vacuum arc in metallic vapor was used as plasma environment in the source. The source worked in pulse mode and generated polychromatic beams of copper ions.

As targets, the plates of $10 \times 10 \times 2 \mathrm{~mm}$ from steel $30 \mathrm{XГCН} 2 \mathrm{~A}$ were used. Before ion implantation, the samples were subjected to heat treatment: quenching with $910^{\circ} \mathrm{C}$ when cooling in oil and subsequent tempering at temperature of $210^{\circ} \mathrm{C}$ during 2 hours. This thermal treatment provides for the achievement of steel 30 ХГСН $2 \mathrm{~A}$ hardness at the level of $45 \mathrm{HRC}$. The implantable surface was polished.

The examination of the surface layers chemical composition has been performed on the JEOL auger spectrometer JAMP-9500F, the electronic probe for auger analysis, which has a diameter of $8 \mathrm{~nm}$, and the spatial resolution of secondary electrons is $3 \mathrm{~nm}$. The instrument, using the secondary electrons mode, allows conducting mapping operation of element composition distribution in augerelectrons and obtaining the profiles of elements concentration as a function of depth through the alternating accumulation of auger spectra and ion etching. The approximation of the concentration profiles of copper in depth has been carried out using the Origin 7.0 [28].

The $x$-ray examination of the plates and the analysis of their texture by means of method of orientation distribution function (ODF) was carried out on the Rigaku diffractometer Ultima IV in CU Ka radiation and DRON-7 diffractometer, equipped with the texture attachment PGTM in Co Ka irradiation.

The dose of the copper implantation of $10^{17} \mathrm{ion} / \mathrm{cm}^{2}$ was as the primary choice. In order to determine the depth dependence of copper ions penetration in the target and changes in the structure of the implanted layer from the implantation mode during experiments, the implantation dose varied within $5 \cdot 10^{16}-10^{18} \mathrm{ion} / \mathrm{cm}^{2}$.

\section{Results of the study}

The surface layers of the plates examined prior to implantation have a distinctive needle-like marten site structure (Figure 1). Plate material is weakly textured, the main deformation components of BCC-metals have been most clearly demonstrated on orientation distribution functions (ODF) $\{001\}\langle 110\rangle$ and $\{111\}\langle 110\rangle$ (Fig.2).

The examination of the layer generated after the implanted layer etching away to a depth of $900 \mathrm{~nm}$, showed that the nature of the microstructure at that depth remained unchanged after copper implantation. The texture type of the plate material remained the same; within the experiment error, the value of the lattice distance of $2.870 \pm 0.001 \mathrm{~nm}$ has not changed

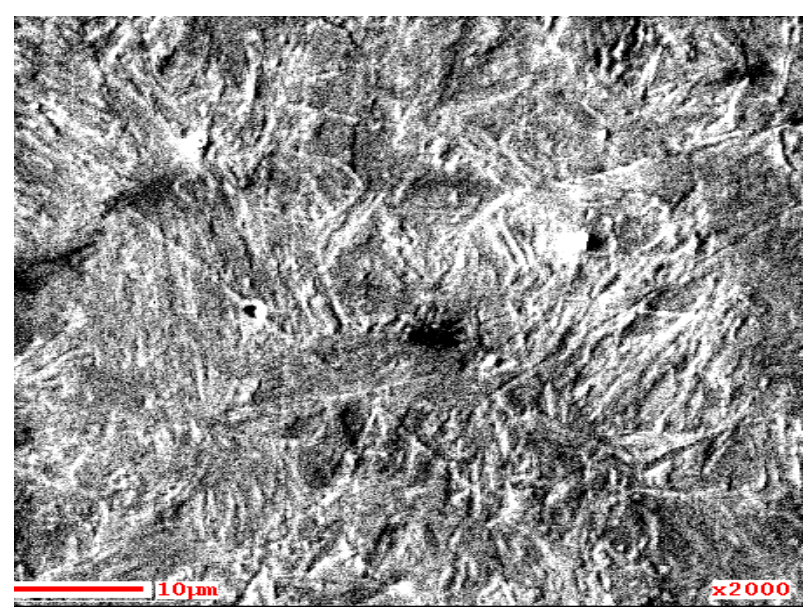

Fig. 1: The Microstructure of the Plate Surface from Steel 30ХГСН2A Prio To Implantation. 


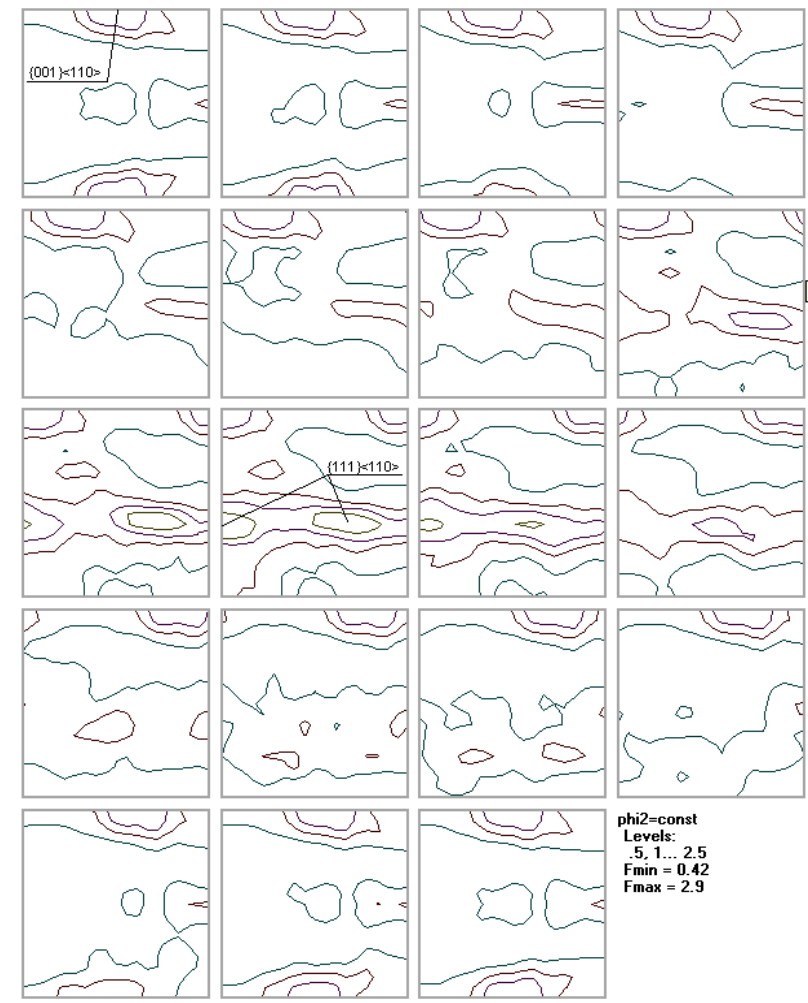

Fig. 2: The Orientation Distribution Function in the Surface Layers of the Plate from Steel 30XГСН2A Prior To Implantation.

Fig. 3 shows a 3D image including auger-spectra obtained from one of the examined plates when etching away a surface from the area of $1 \mathrm{~mm}^{2}$. The elemental composition was determined during spectra recording from areas of $0.2 \mathrm{~mm}^{2}$ and with increment $\mathrm{d}=10 \mathrm{~nm}$ in depth. As you can see, on the first five spectra $(\mathrm{N}=5)$ there is only a maximum that meets the reflex of carbon KLL $(263 \mathrm{eV})$. The first spectral lines of iron $(589,645$, and $700 \mathrm{eV})$ and copper (764, 836, and $916 \mathrm{eV}$ ) are clearly fixed in the spectra obtained after the 6 -th etching cycle. The oxygen lines $(466,482$ and $503 \mathrm{eV})$ were manifested quite clearly in the interval of $5<\mathrm{N}<10$. Profiles construction of carbon, oxygen, iron and copper concentration as a function of depth through the alternating accumulation of auger spectra and ion etching has made it possible to define the content of these components in the plate material depending on the distance to the surface and the nature of its change in depth (Figure 4).

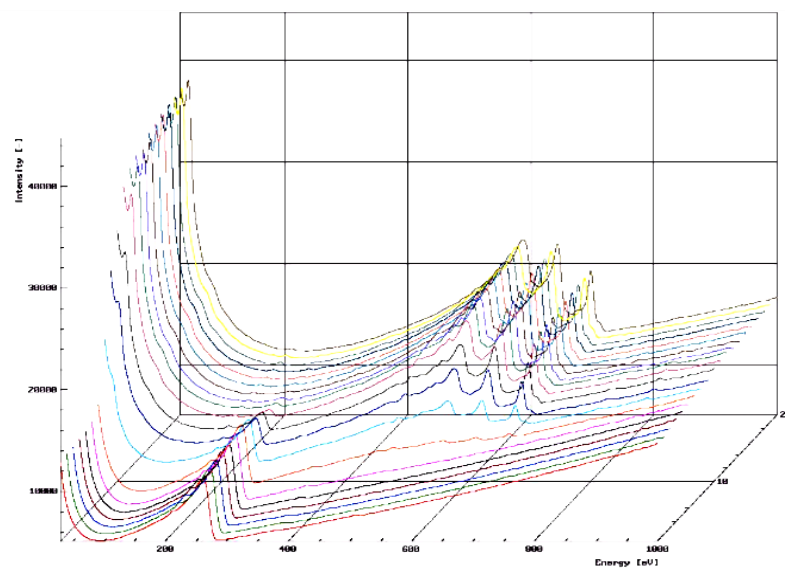

Fig. 3: 3D Image of Spectra Change in Cyclic Etching in Increments of 10 $\mathrm{Nm}$.

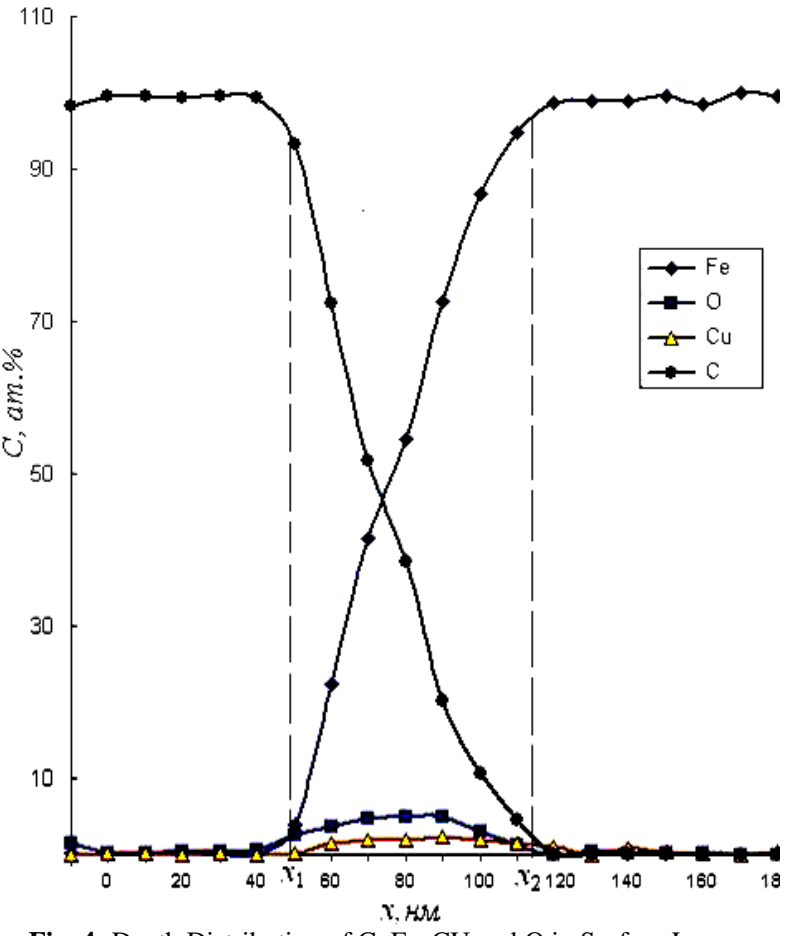

Fig. 4: Depth Distribution of C, Fe, CU and O in Surface Layer.

The distribution of $\mathrm{Fe}, \mathrm{Cu}, \mathrm{C}$ and $\mathrm{O}$ on areas of $300 \times 300 \mu \mathrm{m}$ located at fixed distances from the surface in auger electrons, was examined applying mapping technique (Fig. 5). As you can see, the carbon layer covers almost completely the surface of the plate; during etching away, the carbon area decreases. In the image corresponding to the maximum oxygen content $(\mathrm{N}=8)$, the highest concentration of oxygen corresponds to sections of reduced iron concentration (Figure 5, e, f). Copper is present in these images in the form of dispersed particles (of several nanometers), and is evenly distributed across the surface of the images (Fig. 5, g). 
(A)

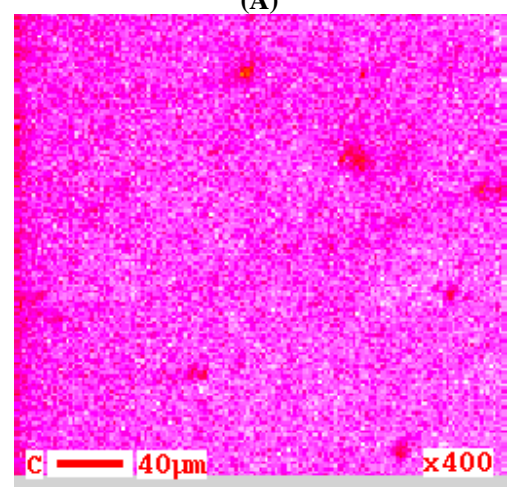

(D)

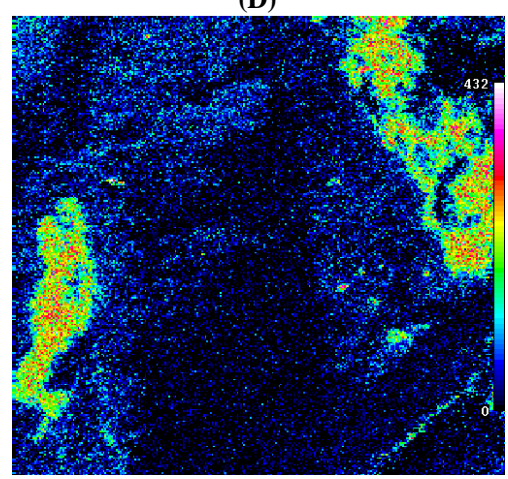

(G)

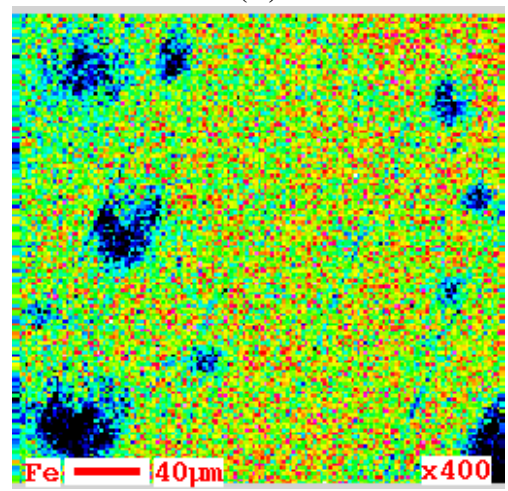

(B)

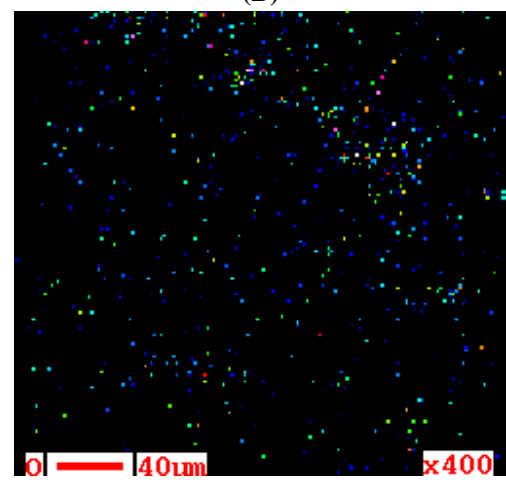

(E)

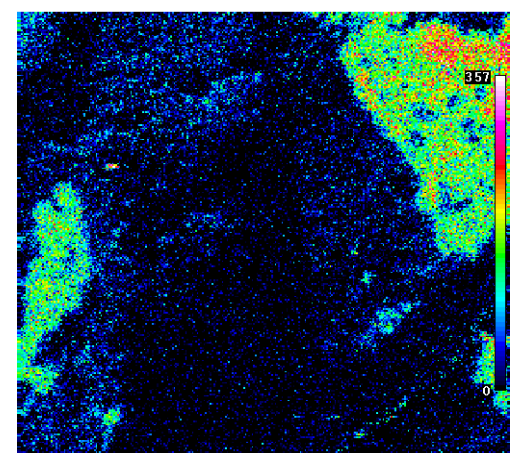

(H)

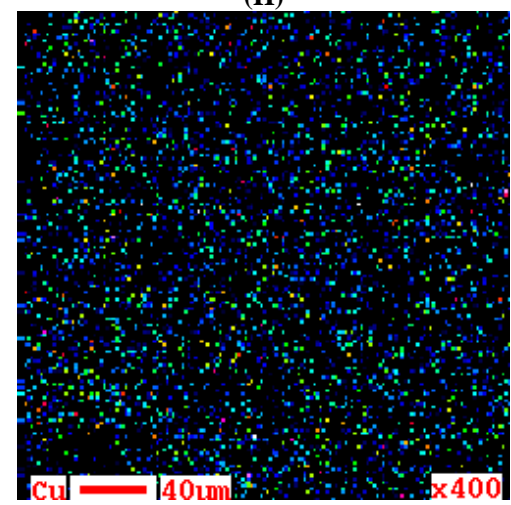

(C)

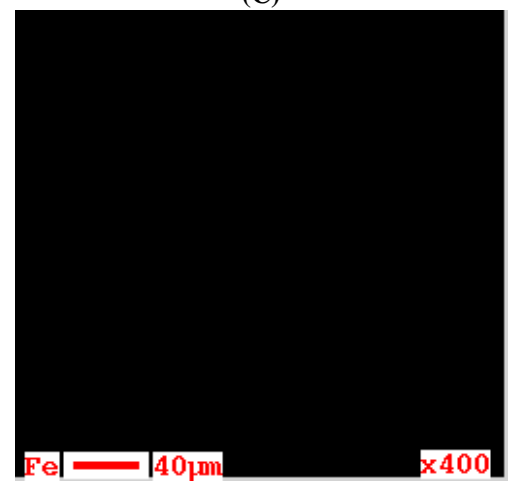

(F)

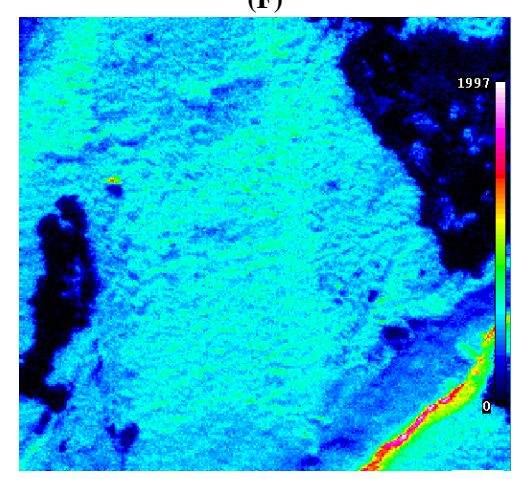

(I)

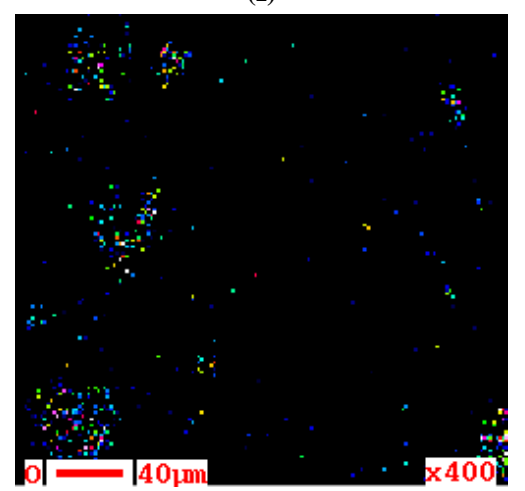

Fi. 5: Distribution of Components in the Implanted Layer on the Surface - Carbon (A), Oxygen (B), Iron (C); at A Distance of 50 Nm from the Surface Carbon (D), Oxygen (E), Iron (F); at the Maximum Level of Copper (100 Nm from the Surface) -Carbon (G), Oxygen (H), Iron (I).

Table 1:. The Results of Approximation of Copper Concentration Dependence in Depth by Means of Gauss Function

\begin{tabular}{|c|c|c|c|c|c|c|}
\hline Sample Numbers & $\mathrm{X}_{\mathrm{C}}, \mathrm{NM}$ & $\mathrm{H}_{\mathrm{C}}, \mathrm{AT} . \%$ & $\mathrm{~A} \mathrm{NM}^{2}$ & $\mathrm{~W}, \mathrm{NM}$ & $\mathrm{X}_{1}, \mathrm{NM}$ & $\mathrm{D}, \mathrm{NM}$ \\
\hline 1 & 99 & 2.2 & 136 & 47 & 50 & 49 \\
\hline 2 & 81.6 & 2.1 & 86.8 & 33.5 & 40 & 42 \\
\hline
\end{tabular}

Note: $x_{c}$ - the position of copper maximum relative to the target surface; $h_{c}$ - height of maxim; A - area under maximum; $\mathrm{W}$ - half width on the maximum half height; $x_{1}$ - thickness of the carbon layer D - distance from maximum to surface of steel target.

From the results of the completed auger experiment it follows that on the plates surface from steel 30ХГСН2A during copper implantation in the ions source with accelerating voltage $30 \mathrm{kV}$ in the vacuum chamber with a gas residual pressure of $8 \times 10^{-4} \mathrm{~Pa}$, the carbon layer with a thickness of several tens of nanometers is formed. Since on the spectral characteristics of the coatings there was no shift of the KLL carbon reflex relative to its standard position $(262.9 \mathrm{eV}$ and $263 \mathrm{eV}$, respectively), it can be assumed it is in the unbound state. In the area located beneath the carbon layer $\mathrm{x}_{1}<\mathrm{x}<\mathrm{x}_{2}$ (intermediate layer in Fig. 4), the iron content in depth increases from a few atomic percent to 95 atomic \%, accordingly, the carbon concentration decreases dramatically. In this area, the high concentration of oxygen with a well-defined maximum peak and the oxygen concentration at a maximum of $\sim 8$ at. $\%$ is fixed. According to the result of the repeated experiment, the close results were obtained (Table 1, sample No. 2).
The distribution of copper in depth in the implanted layer is characterized by the availability of maximum the position of which relative to the surface is slightly different in different experiments and close to 100 nanometers (Fig. 6). The copper concentration $\left(\mathrm{C}_{\mathrm{CU}}\right)$ on the surface is close to zero, in its maximum its value $\mathrm{C}_{\mathrm{CU}} \sim 2$ at. $\%$, further, it smoothly decreases with increasing distance from the target surface. 
(A)

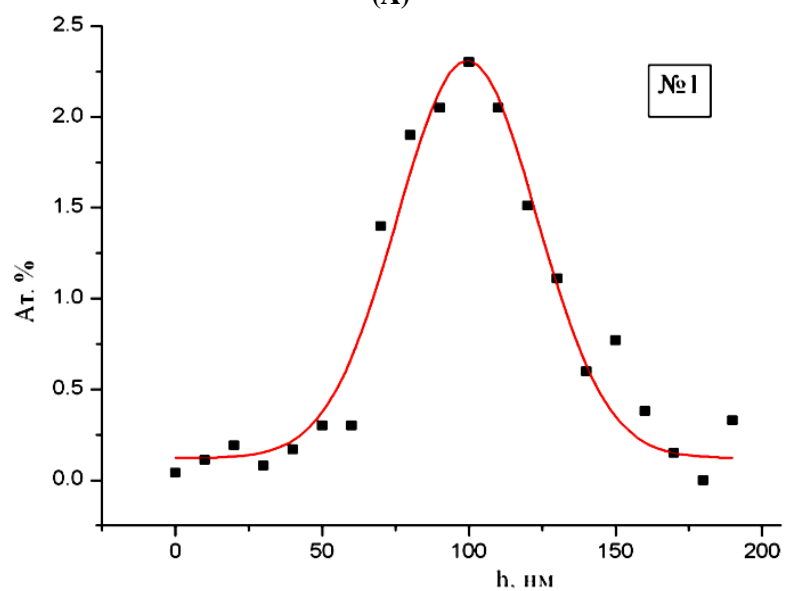

(B)

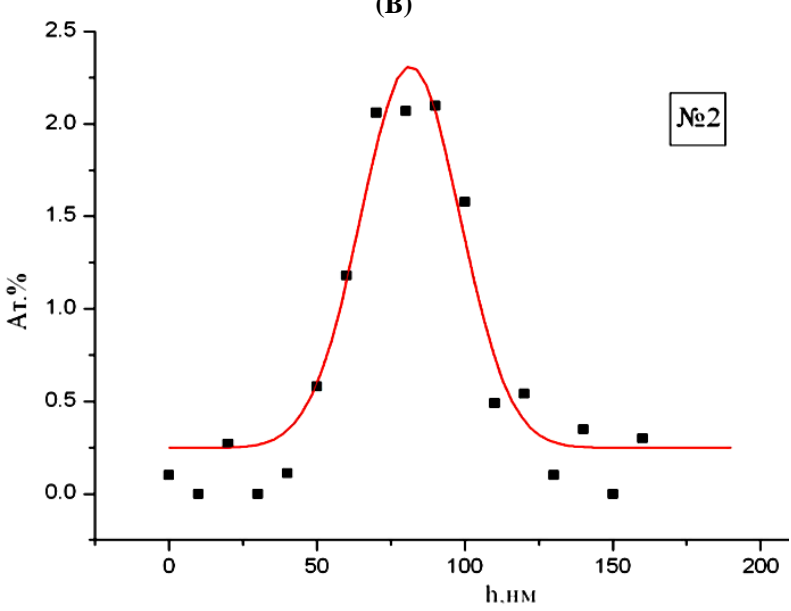

B.

Fig. 6: Results of Approximation of the Copper Concentration Profile in Depth for Two Independent Experiments.

Copper implantation in steel plates was carried out in this work at the accelerating voltage of $30 \mathrm{keV}$. As is known, at such voltage, the elastic contribution to the braking process of the implantable particles [20] dominates and the distribution in depth is described by the Gauss function. The obtained concentration dependence of copper in depth was approximated with the help of function

$$
y=y_{0}+\frac{A}{w \sqrt{\frac{\pi}{2}}} \cdot e^{-2\left(\frac{x-x_{c}}{w}\right)^{2}}
$$

Where XC - the position of maximum, w - the half width of the maximum on the half of its height, A - the area under maximum. As shown in the approximation results (Table 1, Fig. 6), in the surface layers studied, the maximum of copper concentrations are located at $90 \mathrm{~nm}$ depth from the target surface, and the height of maximums is $\sim 2$ at. $\%$.

Table 2: Shows the Size of the Mosaic Blocks D (the Magnitude of the Coherent Scattering Regions) and the Micro Deformation of the Crystal Lattice E, which was Defined According to Diffraction Peak Broadening by the Harmonic Analysis Method.

\begin{tabular}{|c|c|c|c|c|c|c|c|}
\hline Steel grade & Type of treatment & Parameter a, nm & $\Delta \mathrm{a} / \mathrm{a}, \%$ & Size of blocks, $\mathrm{nm}$ & $\Delta \mathrm{D} / \mathrm{d}, \%$ & Micrdefor mations, $\varepsilon \cdot 10^{-2}$ & $\Delta \varepsilon / \varepsilon$ \\
\hline \multirow{2}{*}{ 30ХГСН2А } & HT & 0.2896 & - & 33.2 & - & 0.316 & - \\
\hline & $\mathrm{HT}+\mathrm{I}$ & 0.2904 & 0.28 & 25.6 & 23.0 & 0.327 & 3.6 \\
\hline \multirow{2}{*}{45} & HT & 0.2877 & - & 39.8 & - & 0.273 & - \\
\hline & $\mathrm{HT}+\mathrm{I}$ & 0.2878 & 0.19 & 37.4 & 5.1 & 0.268 & -2.6 \\
\hline
\end{tabular}

The magnitude of the change in the dislocation density of steel resulting from the implantation of copper ions is consistent with the nature of the mosaic blocks size change D (Table 3). For comparison, the dislocation density was masured in steel $30 \mathrm{XГCH} 2 \mathrm{~A}$ and steel 45 .

The minimum change of sizes of mosaic blocks was obtained for steel 45 and for the same steel, the minimum relative change in dislocation density equal to $2.6 \%$ was obtained. Steel $30 \mathrm{XГCH} 2 \mathrm{~A}$ has the maximum change of the mosaic blocks size and the densities of dislocation.

For the virgin samples of steel $30 \mathrm{XГСН} 2 \mathrm{~A}$ (unimplanted), the main type of dislocation substructure is reticular and the structure of dislocation chaos (Figure 7, a). Dislocation structure of the samples modified layer implanted by only copper and lead ions has a reticular structure (Fig. 7, b).

Table 3: Change in the Density of the Dislocations in the Implanted Layer of Steel 30ХГСН2A and Steel 45

\begin{tabular}{|c|c|c|c|c|c|}
\hline Steel grade & $\begin{array}{l}\text { Type of treat- } \\
\text { ment }\end{array}$ & $\begin{array}{l}\text { Upper limit } \rho \varepsilon \cdot 1011 \text {, } \\
\mathrm{cm}-2\end{array}$ & $\begin{array}{l}\text { Lower limit } \rho d \bullet 1011 \text {, } \\
\mathrm{cm}-2\end{array}$ & $\begin{array}{l}\text { True value } \rho \text { true } \bullet 1011, \\
\mathrm{~cm}-2\end{array}$ & $\begin{array}{l}\text { Relative change } \rho \text { true } 1011 \text {, } \\
\%\end{array}$ \\
\hline \multirow{2}{*}{ 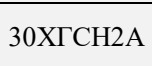 } & HT & 2.76 & 2.66 & 8.57 & - \\
\hline & $\mathrm{HT}+\mathrm{I}$ & 4.55 & 2.95 & 11.74 & 37.1 \\
\hline \multirow{2}{*}{45} & & 1.91 & 1.94 & 6.09 & - \\
\hline & $\mathrm{HT}+\mathrm{I}$ & 2.12 & 1.84 & 6.25 & 2.6 \\
\hline
\end{tabular}




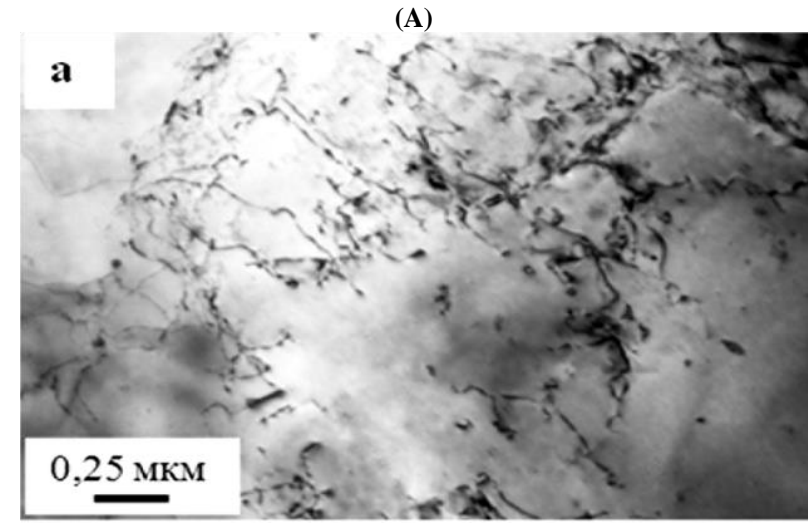

(B)

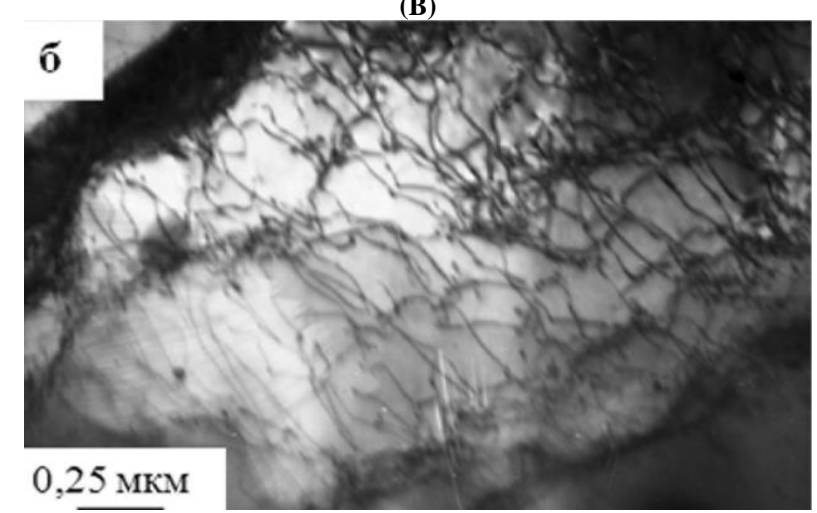

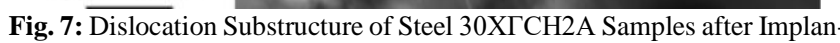
tation.

a) Chaotic distribution (original material).

b) Reticular after the implantation of the copper ions.

Structure analysis of the implanted layer and the distribution of the copper atoms in it shows that the strengthening of the steel $30 \mathrm{XГCH} 2 \mathrm{~A}$ surface layer is possible through the formation of copper solid solutions in iron, as well as by reducing the grains size.

The formation of copper oxide and free carbon in the structure of the implanted layer may be the additional factor that enhances wear resistance.

With the help of the optical metallography, the effects of the radiation dose of copper atoms on the structure of the steel $30 \mathrm{XГCH} 2 \mathrm{~A}$ surface layer were investigated. The results of the optical metallography show (Fig. 8) that the steel 30ХГСН2A post-implantation structure significantly differ from the standard processing mode

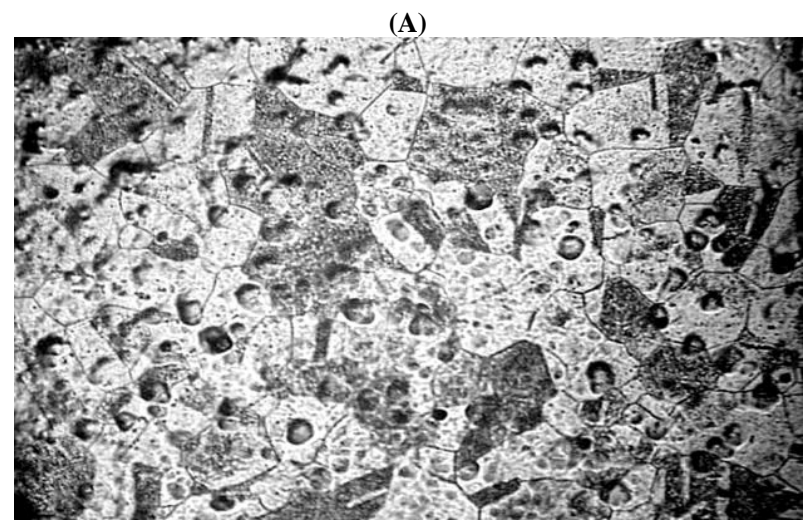

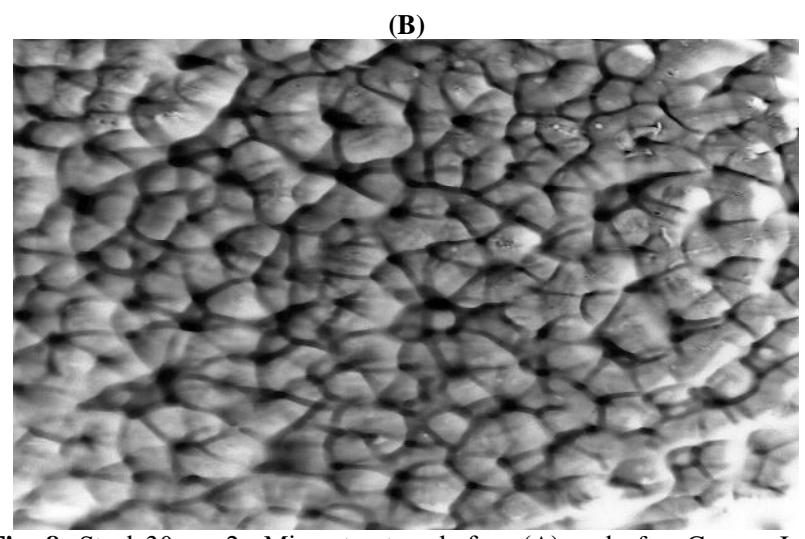

Fig. 8: Steel 30хгсн2a Microstructure before (A) and after Copper IonBeam Processing (B), X 400.

The measurements of average grain size of steel 30ХГСН2A by intercept method after various modes of ion implantation of copper atoms showed (Table 4) that during ion implantation at dose $\mathrm{D}=$ $1.0 \cdot 10^{17} \mathrm{ion} / \mathrm{cm}^{2}$, the grain size is equal to $11 \mu \mathrm{m}$ that is much smaller than after the standard mode and other modes of ion implantation of copper atoms.

Table.4:.Average Grain Size Dependence from Irradiation Modes

\begin{tabular}{|c|c|c|c|}
\hline \multicolumn{3}{|c|}{ Irradiation mode with copper ions } & \multirow[b]{2}{*}{$\begin{array}{l}\text { Average grain } \\
\text { size, } \mu \mathrm{m}\end{array}$} \\
\hline $\begin{array}{l}\text { Energy, } \\
\text { Kev }\end{array}$ & $\begin{array}{l}\text { Dose, } \\
\text { ion } / \mathrm{cm}^{2}\end{array}$ & $\begin{array}{l}\text { Duration of irradia- } \\
\text { tion, } \mathrm{h}\end{array}$ & \\
\hline- & - & - & 21 \\
\hline 2.5 & $5 \cdot 110^{16}$ & 0.4 & 15 \\
\hline 2.5 & $10^{17}$ & 0.8 & 11 \\
\hline 2.5 & $5 \cdot 110^{17}$ & 1.3 & 14 \\
\hline 2.5 & $10^{18}$ & 1.7 & 18 \\
\hline
\end{tabular}

It is also clearly seen that the steel $30 \mathrm{XГCH} 2 \mathrm{~A}$ microstructure before and after ion-beam processing is characterized by the grains availability of different types and the presence of quench twins that are present in almost every grain.

The obtained values of surface texture parameters, the most significant of which are Wa (waviness) and Ra (average roughness), show that the change in the micro geometry of the surface largely depends on the dose of alloying (Table 5).

Table 5:.Surface Texture Parameters of Steel 30ХГСН2A Samples

\begin{tabular}{llll}
\hline Sample & $\begin{array}{l}\text { Dose of alloying ad- } \\
\text { dition, cm-2 }\end{array}$ & $\begin{array}{l}\text { Option } \\
\text { Wavi- } \\
\text { ness, nm }\end{array}$ & $\begin{array}{l}\text { Medium } \\
\text { roughness, HM }\end{array}$ \\
Raw steel & - & 512 & 155 \\
Copper ions & $2,5 \cdot 1017$ & 655 & 188 \\
implantation & $5 \cdot 1017$ & 518 & 173 \\
& 1018 & 432 & 162 \\
\hline
\end{tabular}

During the implantation of the copper ions, the average roughness noticeably increases (from 155 to $188 \mathrm{~nm}$, respectively at dose of alloy $2.5-210^{17} \mathrm{~cm}^{-1}$ ). The copper ions at the same dose of alloying practically do not change RA. Increase in the implantation dose does not significantly change the surface texture.

At the same time, the waviness increases significantly at dose of alloying $2.5 \cdot 10^{17} \mathrm{~cm}^{-2}$, although at dose of alloying increase it considerably decreases.

To illustrate it, Figure 9 shows three-dimensional images of sample surfaces. The most interesting thing is that with the dose of alloying $2.5 \cdot 10^{17} \mathrm{~cm}^{-2}$, the copper ions significantly "loosen" surface, increasing both the waviness and the roughness. However, the implantation continuation leads to leveling the relief shape and lowering the height of local irregularities.

Thus, we can confidently say that at copper ion implantation in steel $30 \mathrm{X} \Gamma \mathrm{CH} 2 \mathrm{~A}$ there is a change in surface geometry, in particular such parameters as Ra and WA. 


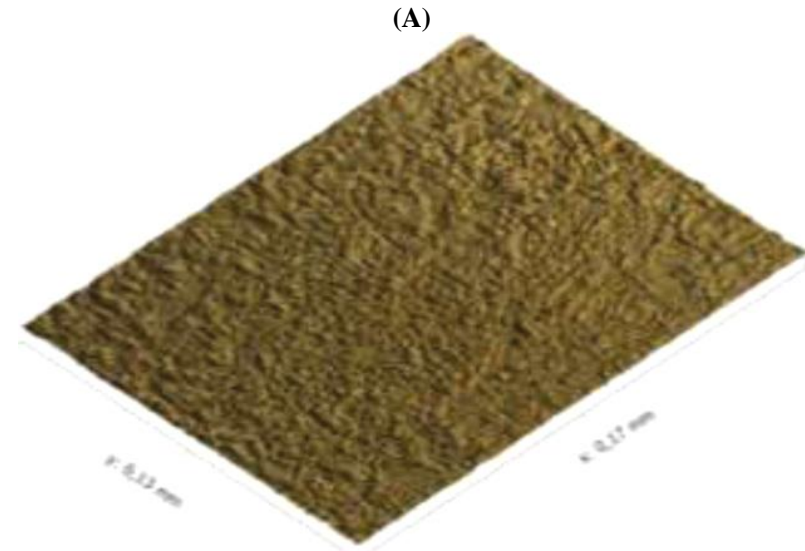

(B)

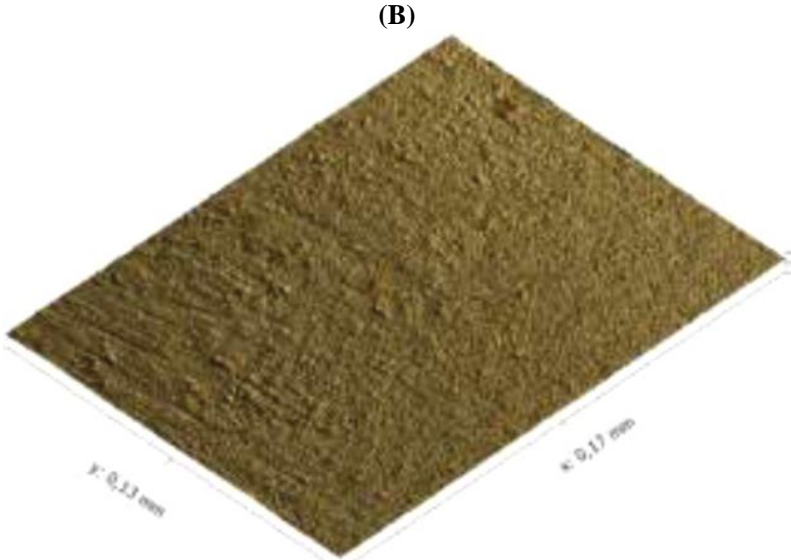

Fig. 9: Three-Dimensional Images of the Steel 30хгсн2a Samples Surfaces Obtained with the Help of Gwydion Program. Increase.

300 , dose of alloying: $\mathrm{a}-2.5 \cdot 10^{17} \mathrm{~cm}^{-2} ; \mathrm{b}-5 \cdot 10^{17} \mathrm{~cm}^{-2}$;

The elemental composition of the surface layers of steel $30 \mathrm{XГСН} 2 \mathrm{~A}$ was investigated by means of auge spectroscopy techniques depending on the implantation dose (Fig. 10). The maximum concentration of copper is 2.7 and 12 at. \% at doses of irradiation $1 \cdot 10^{17} ; 5 \cdot 10^{17} ; 1 \cdot 10^{18} \mathrm{ion} / \mathrm{cm}^{2}$ respectively. As you can see (Fig. 10), with increase of implantation dose, the maximum concentration shifts toward larger depths and the thickness of the implantation layer increases: from 180 to $400 \mathrm{~nm}$.

The microstructure of the surface layers of steel $30 \mathrm{XГCH} 2 \mathrm{~A}$ has been studied after the ion impact. It was established that according to the result of ion impact, there is a significant change in the grain status of steel. With the increase in the dose of irradiation, the longitudinal size of grains is reduced, and at the maximum dose is $0.84 \mu \mathrm{m}$.

With the change in the implantation dose, there is also a decrease in the anisotropy coefficient. A significant change in structure is associated primarily with the energy effect in conditions of implantation. The increase in the dose is due to the increasing duration of implantation. The materials restructuring takes place both because of energy effect and in the result of local temperature increase in conditions of implantation. The increase in the dislocation density in the implanted materials is observed.

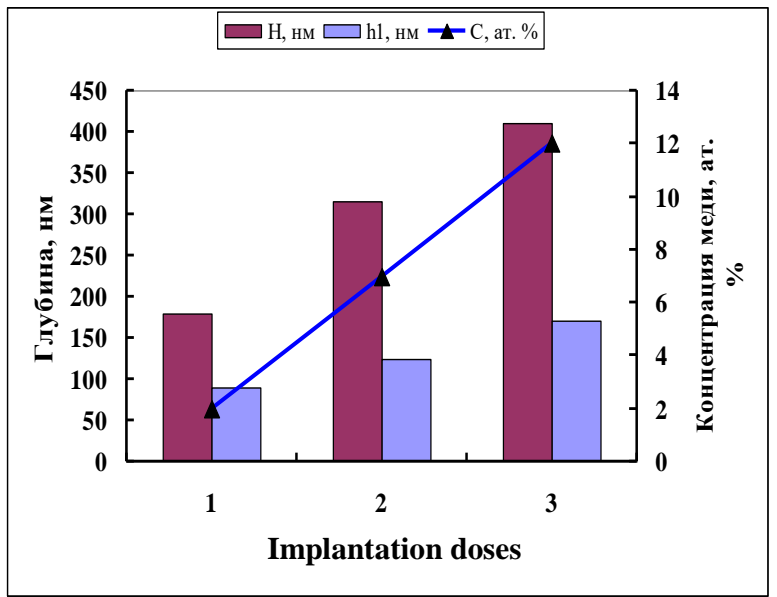

Fig. 10: the Influence of the Implantation Dose on the Depth of Ions N Penetration (Thickness of the Implanted Layer), the Depth $\mathrm{H}_{1}$ of the Maximum Copper Concentration Location and the Value $\mathrm{C}$ of Copper Maximum Concentration: $1-1 \cdot 10^{17} ; 2-5 \cdot 10^{17} ; 3-1 \cdot 10^{18} \mathrm{ion} / \mathrm{cm}^{2}$.

An electron-microscopic study of the dislocation structure of the steel 30ХГСН2A surface layer conducted after the implantation by copper ions showed (Fig.11) that at the depth exceeding the ions range, there is a heterogeneous distribution of the dislocations, long straight dislocations with sliding traces and a dislocation loops, possibly of vacancy origin are met.

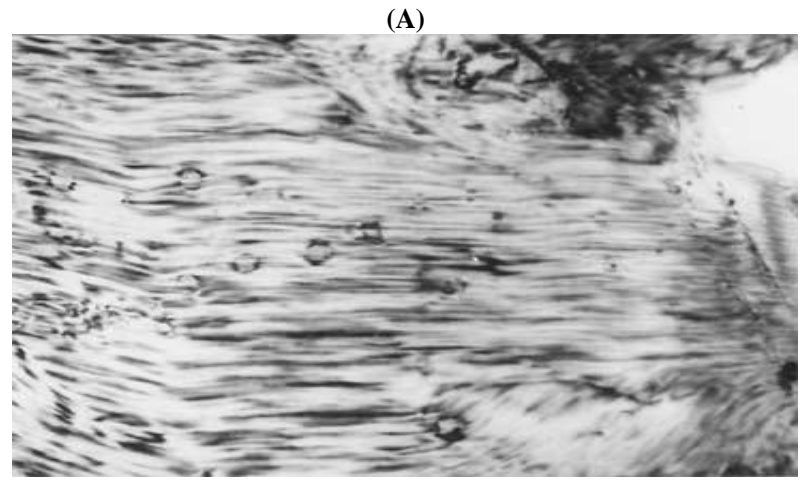

(B)

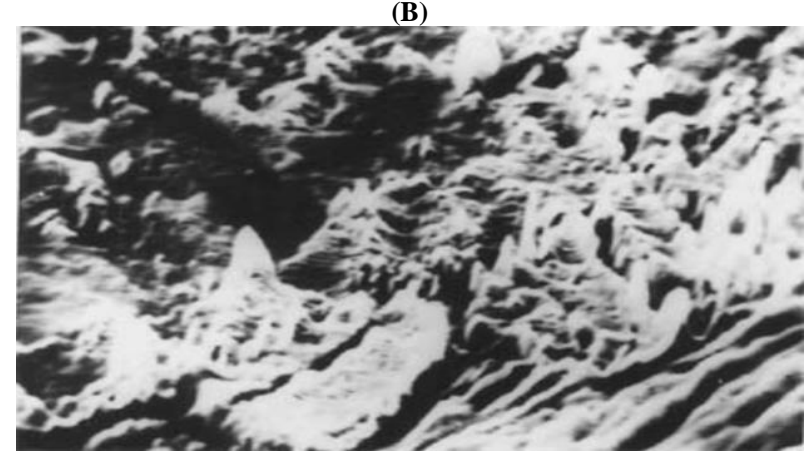

(C)

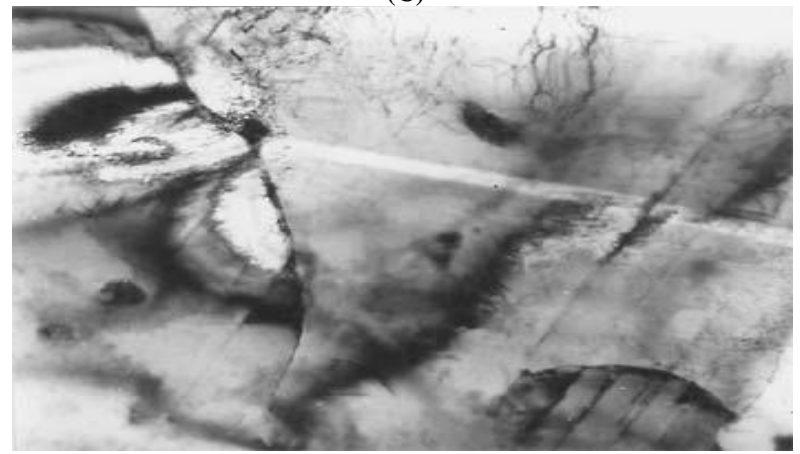

Fig. 11: The Microstructure of Steel 30ХГСН2A after Ion Implantation 
a) Dislocation loops of vacancy origin (depth 5-10 $\mu \mathrm{m}, \mathrm{x} 7000$ ).

b) Dislocation structure beneath the surface of the implanted layer (depth 15-30 $\mu \mathrm{m}$, x 14000).

c) Surface spray with ion implantation of copper $5 \times 10^{17}$ ion $/ \mathrm{cm}^{2}$

Within the framework of this work paper, the surface layers of steel $30 \mathrm{XГCH} 2 \mathrm{~A}$ (strip $100 \times 20 \times 2 \mathrm{~mm}$ ), modified in the conditions of high dose implantation by the ions of $\mathrm{Cu}+\mathrm{Pb}$ and $\mathrm{Cu}+\mathrm{Fe}$ were studied. A dose of implantation was $1 \cdot 10^{17} \mathrm{ion} / \mathrm{cm}^{2}$. Accelerating voltage $-30 \mathrm{kV}$.

Through study of the implanted layer by the atomic-emission spectroscopy method, the chemical composition on the surface in five points along the sample length to the depth of $400 \mathrm{~nm}$ was determined.

Distribution of components concentration over thickness of the implanted layer by ions of $\mathrm{CU}+\mathrm{Fe}$ are presented in Fig. 12.

As can be seen from Fig.12, the dependence of concentrations from the etching depth reaches almost zero after $100 \mathrm{~nm}$. Copper concentration is fixed up to $400 \mathrm{~nm}$. The most dramatic change in the copper concentration $\left(\mathrm{C}_{\mathrm{Cu}}\right)$ is observed at the depth of up to $60 \div 80$ $\mathrm{nm}$. As a parameter characterizing the thickness of the implanted layer $(\mathrm{t})$, the value $\mathrm{t}_{0}$ at which the value $\mathrm{dC}_{\mathrm{Cu}} / \mathrm{dt} \sim 0$ was selected. In the first approximation, the ratio of the layers thickness enriched by the implantable components corresponds to the rule $\delta \sim \mathrm{m}_{1} / \mathrm{m}_{2}{ }^{\circ}$ $\mathrm{Z}_{2}^{2} / \mathrm{Z}_{1}^{2}$, where $\mathrm{m}$ - mass, $\mathrm{Z}$-ionic charge.

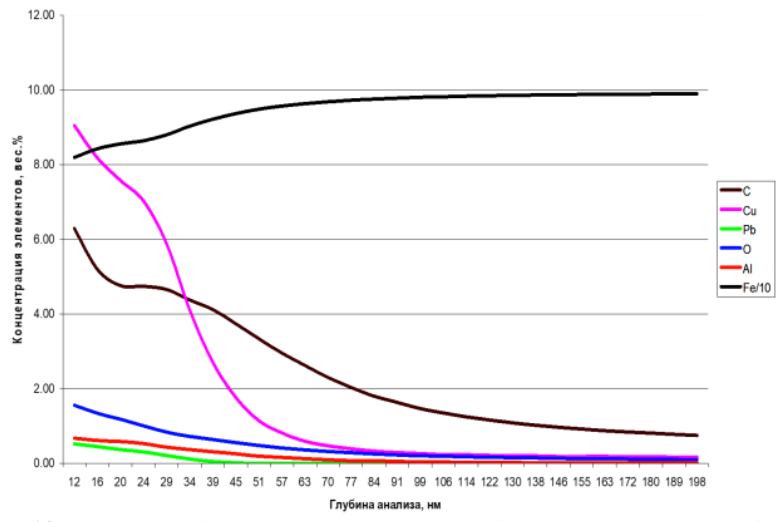

Fig. 12.: Change of Components Concentration Over Thickness of the Implanted Layer By Ions of $\mathrm{Cu}+\mathrm{Fe}$.

In this case, the copper concentration in the surface layer reaches 8.5-9.1 wt \% for carbon concentration 6.0-6.3 wt \%.

In case of ion implantation of $\mathrm{Cu}+\mathrm{Pb}$ ions (Fig. 13), the increase in the concentration of free carbon to $21.5-22.4 \mathrm{wt}$.\% is clearly observed during the concentration of implanted copper atoms at the level of 9.2-9.7 wt. \%. It can be noted that during ion implantation of $\mathrm{Cu}+\mathrm{Pb}$, in comparison with the option of ion implantation of $\mathrm{Cu}+\mathrm{Fe}$, the increase in carbon concentrations by about 3.5 times is observed.

The chemical composition of the target implanted layer was defined as the chemical composition at depth of $10 \mathrm{~nm}$. It appeared that one of the main elements of the coating surface is carbon $(\sim 6 \%)$. The components of cathode implanter are contained in the surface layer in ratios significantly different from its chemical composition.

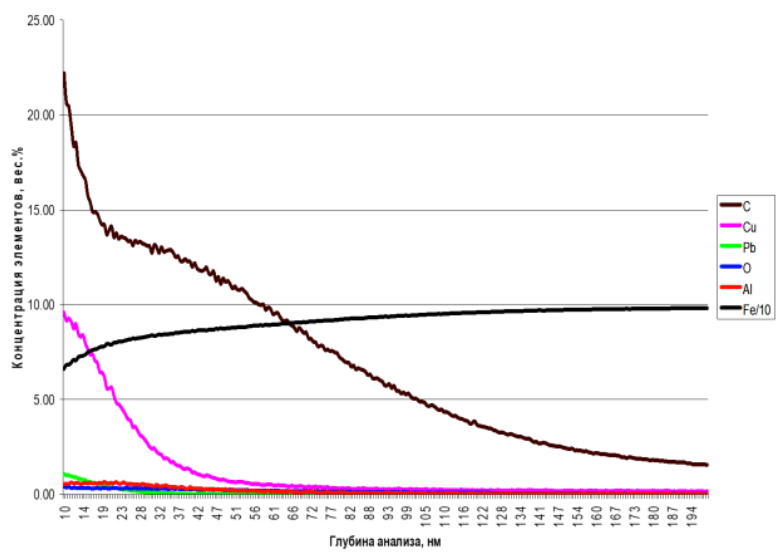

Fig. 13: Change of Components Concentration over Thickness of the Implanted Layer During Ion Implantation of $\mathrm{CU}+\mathrm{Fe}$.

To study the implanted layer with the auger spectroscopy method, fragment from the sample central part was cut out. Before registering the auger spectra, the surface layer (absorbed) was etched away from the surface layer to depth of $10 \mathrm{~nm}$.

The highest intensity on the auger spectra of the surface corresponds to carbon. The peaks matching the iron (Fig. 14) are quite intense. During etching away, the intensity of Fe peaks increases significantly, and the carbon intensity decreases. The peaks that correspond to $\mathrm{Cu}$ are clearly fixed. To estimate $\mathrm{Pb}$ content is difficult because its main peak is superimposed on the carbon peak. In order to obtain information on the distribution of alloying components in scope of the implanted layer, the study was conducted on the distribution of their concentrations on the area of $10 \mu \mathrm{m}$ during etching away. The area studied was located in the central part of the sample, where the elements concentration was previously defined.

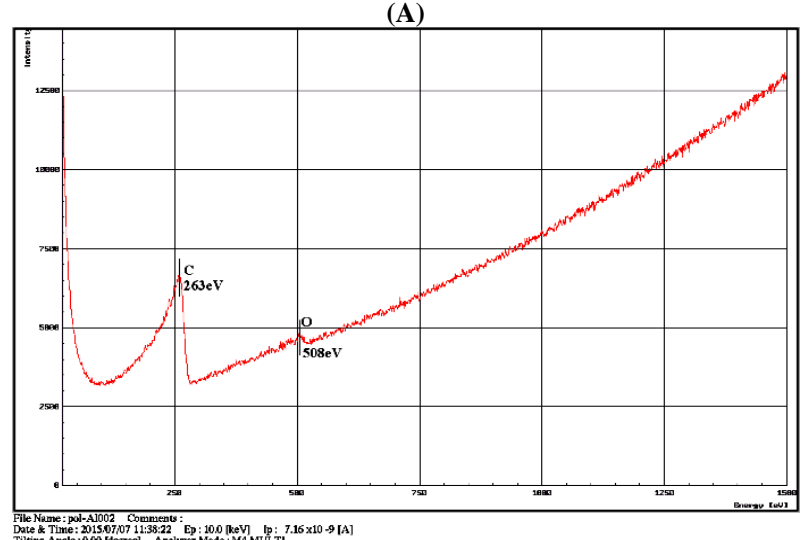

(B)

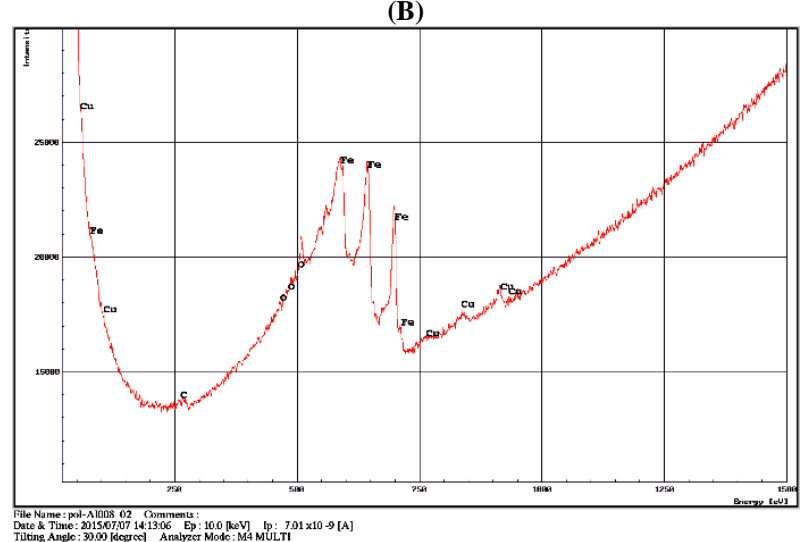

Fig. 14: Auger-Spectra of Target Surface (A) and after 90 Nm Layer Etching Away (B) 
It has been established that on the surface (after etching away of the adsorbed layer $10 \mathrm{~nm}$ ), the major part of the area studied is the area where the carbon concentration is extremely high. From the comparison of $\mathrm{Fe}$ and $\mathrm{O}$ distribution over the surface, it follows that the material contains areas (with size $\sim 3 \mu \mathrm{m}$ ) of iron oxides.

During etching away, the carbon-enriched area is dramatically reduced and the area occupied by iron increases. In addition to oxides, the areas corresponding to iron carbide appear. After further etching away, almost all over the surface the iron content is maximum, but there are higher-carbon areas $(\sim 1-2 \mu \mathrm{m})$ and small $(\sim 0.5 \mu \mathrm{m})$ inclusions where the carbon content is high.

\section{Discussion}

As noted above, the carbon enrichment of the plates surface layers made of steel $30 \mathrm{XГCH} 2 \mathrm{~A}$ during copper implantation was observed earlier [11]. This effect was associated with sorption of hydrocarbons due to the lack of a high vacuum. As it follows from the assessment of the quantitative content of $\mathrm{C}, \mathrm{Fe}, \mathrm{O}$ and $\mathrm{Cu}$, in this experiment performed in vacuum of $8 \cdot 10^{-4} \mathrm{~Pa}$, on the steel plates

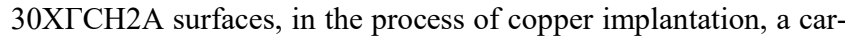
bon layer of $\sim 50 \mathrm{~nm}$ is formed. The formation ability of carbon layer of such thickness only due to residual gases under these conditions is not obvious. It can also be assumed that carbon in the surface layer is accumulated in the spraying process during implantation and due to its uphill diffusion to the surface from the matrix. In this context, it is evident that the experiments on the copper implantation using the existing techniques in non-carbon metals, such as pure iron or titanium, are of interest.

In [28-30], the computer modelling of the process of the copper ions introduction into steel $30 \mathrm{XГСН} 2 \mathrm{~A}$ and profiling of the distribution in depth when implanting at the accelerating voltage of $30 \mathrm{keV}$ and dose $10^{17} \mathrm{i} / \mathrm{cm}^{2}$ was carried out by the Monte Carlo method using the program TRIM (SRIM) and the free distributed library of program Geant 4 . The experimental regularities of copper distribution in surface layers after implantation is consistent with the calculated concentration dependencies of copper content in depth, assuming that the carbon layer on the surface of the coating has been formed during the implantation process. In this case, in determining the position of the maximum copper concentration, the count should be taken not from the surface of the carbon layer, but from the zero value of the iron concentration or from the edge of the steel plate (x 1 in Fig. 4). As can be seen from Fig. 4 and Table 1, this value equals to $\sim 40 \mathrm{~nm}$, i.e close enough to the calculated value. The possible discrepancies between these values appear to be due to the fact that the high-energy implantable copper ions are distributed in the areas where the content of iron heavy ions is significantly smaller than in the implantable steel and its structure is substantially defective (layer $\mathrm{x}_{1}<\mathrm{x}_{\mathrm{x}}<\mathrm{x}_{2}$ in Fig. 4).

The presence of oxygen at depth of $\sim 70 \mathrm{~nm}$ from the surface appears to be due to the presence of the oxide film formed on the surface of the steel plate prior to implantation. As noted above, the oxides films of $\mathrm{Fe} 2 \mathrm{O} 3, \mathrm{Fe}_{3} \mathrm{O}_{4}, \mathrm{FeO}$ are formed on the iron at room temperature, and its increase leads to the rapid increase in the speed of their growth. The oxide film on the surface of steel plate 30HGSN2A in this experiment may have been formed during the heat treatment and partially retained in the further preparation of the surface for implantation. Oxygen in the implanted layer is likely to be associated with iron oxides (on $\mathrm{Fe}$ and $\mathrm{O}$ distribution maps, the maximum oxygen concentrations correspond to lower iron concentrations).

The improvement of the tribological properties of the items surface manufactured from steel $30 \mathrm{XГCН} 2 \mathrm{~A}$, implanted by various ions, including copper in $[30,31]$ are associated first of all with the formation of the fragmented surface layer, the hardening of which is achieved through dispersion, dislocation and grain boundary mechanisms. The carbon layer formed on the surface resulted from the copper implantation and the layer enriched with copper should be considered as a solid lubricant that enhances the tribological characteristics.

\section{Conclusion}

From the study results obtained by auger spectroscopy techniques of the surface layers generated during copper implantation into the plate from steel 30ХГСН2A by means of impulse source of ions in the vacuum chamber with gases residual pressure $8 \times 10^{-4} \mathrm{~Pa}$, it follows that they can be represented as two sublayers. The top sublayer of $\sim 50 \mathrm{~nm}$ thick, consisting of carbon which is most probably was formed in the process of implantation, and the lower sublayer of the complex chemical composition within which the iron concentration increases in depth from 0 at. \%. to 95 at.\%. The copper concentration profile in depth is characterized by a maximum availability located at distance of $\sim 40-50 \mathrm{~nm}$ from the plate surface. Taking into account the magnitude of the accelerating voltage (30 $\mathrm{kV}$ ), it was approximated by the Gauss function, which is usually used to describe the distribution of implantable components for the case of the dominant elastic contribution to the braking process of the implantable particles. Resulted from copper implantation in the surface of steel $30 \mathrm{XГCH} 2 \mathrm{~A}$, the surface layers consisting of a surface carbon layer and a layer containing copper, acting as a solid lubricant, can improve the tribological characteristics of the products made of steel $30 \mathrm{XГСН} 2 \mathrm{~A}$. 


\section{References}

[1] Bykovsky Yu. A., Nevolin V. N., Fominsky V. Yu. Ion and Laser Implantation of Metallic Materials. - M.: Energoatomizdat, 1991. $237 \mathrm{p}$.

[2] 2. Ion implant/under the editorship of J. K. Hirvonen: Transl. from English: - M. Metallurgy, 1985. 392 p.

[3] Ion Doping of Semiconductors: Transl. from English/ J. Meyer, L. Eriksson, J. Davis; Under the editorship of Ph.D. in Physics and Mathematics Guseva V.M. - Moscow: Mir, 1973. -296 p.

[4] Guseva M.I. Ion Implantation in Metals.// Surface. Physics, Chemistry, Mechanics. 1982. -No. 4. - p. 27-50.

[5] Didenko A.N., Ligachev A.E., Kurakin I.E. Effects of Charged Particles Beams on the Surface of Metals and Alloys. -M.: Energoatomizdat, 1987. - 184 p.

[6] Komarov F.F. Ion implantation into metals. -M.: Metallurgy, 1990. $216 \mathrm{p}$.

[7] Bykovsky Yu. A., Nevolin V. N., Fominsky V. Yu. Ion and Laser Implantation of Metallic Materials. - M.: Energoatomizdat, 1991. 237 p.

[8] Wilbur P.J., Davis J.A., Williamson D.L. et al. High current density broad-beam boron ion implantation//surf. Coat. Techn. 1997. -V. 96 -P. 52-57.

[9] Ovchinnikov V. V., Kozlov D. A., Yakutina S. V. The Influence of the Copper Ion Implantation on the Properties of the Structural Steel 30ХГСН2A.// Strengthening Technology and Coatings. 2009. No.10 p.16-23

[10] Ovchinnikov V. V., Kozlov D. A., Yakutina S. V. The Study of the Surface Properties of Steel 30хгсн2a After Copper Ion Implantation // Mechanical Industry and Engineering Education. 2009. - No. 2. P. 32-37.

[11] Yakutina S. V., Ovchinnikov V. V. Kozlov D. A., Nemov A. S. Effect of Copper and Lead Ions Implantation on Steel 30ХГСН2A Properties. // Mechanical Industry And Engineering Education, 2010. No. 4. P.38-45.

[12] Ovchinnikov V. V. Kozlov D. A., Krit B. L., Stolyarov V. V. IonBeam Modification of Tribological Properties of Chromium Steel. // Physics and Chemistry of Materials Processing. 2010. No. 1. P.5053.

[13] Semendeeva O.V., Uchevatkina N.V., Ovchinnikov V.V. Metallurgical and Technological Features of Titanium Alloys Implantation.// Mechanical Engineering and Engineering Education. -No. 2.-c. 17 28.

[14] Yakutina S. V., Ovchinnikov V. V. Kozlov D. A., Nemov A. S. Properties and Composition of the Steel 30ХГСН2A Surface Depending on the Irradiation Dose by Copper and Lead Ions. // News of Moscow State Industrial University. 2010. - №3(20). - S. 15-20.

[15] 6. Sharkeev Yu.P., Ryabchikov A.I., Kozlov E.V., Kurzina I.A., Stepanov I. B., Bozhko I.A., Kalashnikov M.P., Fortuna S.V., Sivin D. O. High-Intensity Ion Implantation - Method of Forming Finely Dispersed Intermetallides in Surface Layers of Metals. // Izvestiya Vuzov. Physics. 2004. - No. 9. - p. 44-52.

[16] Prinyavichyus L., Dudonis Yu. Modification of Solid Bodies Properties by Ion Beams. Vilnius: Mokslas, 1980. - $242 \mathrm{p}$.

[17] 8. Byeli, A.V., Kukareko V.A., Lobodaeva O.V. et al. Ion-Beam Processing of Metals, Alloys And Ceramic Materials. Minsk: Institute of Physics and Technology, 1998. -220 p.

[18] Ovchinnikov V. V., Yakutina S. V., Kozlov, D. A. The Influence of Copper and Lead Ions Sequence on Their Distribution in the Surface Layer of Steel 30ХГСН2A.// Strengthening Technologies And Coatings - 2011. -No.12 - p. 26-31.

[19] Didenko A.M., Ligachev, A.E., and Kurakin, K.B. Impact of Charged Particle Beams on the Surface of Metals and Alloys. - M.: Energoatomizdat, 1987. - 184 p.

[20] Borovin Yu.M., Ovchinnikov V.V. Ion Implantation of Surface Layers of Machine Parts.// High Technologies In Mechanical Engineering. 2011. - No. 6. - P. 29-39.

[21] Ovchinnikov V. V., Serikova E. A., Yakutina S. V. The Influence of Implantation by Monotectic Copper Alloy with Lead, Additionally by Alloyed Tin on the Wear Resistance of Steel 30HGSN2A.// Strengthening Technologies and Coatings. 2012. No.4. P. 27-31.

[22] Lukyanenko E. V., Ovchinnikov V. V., Borodin Y. M., S. V. Akhutina The Influence of Contact Monotectic Alloy $\mathrm{Cu}-\mathrm{Pb}$ Used for the Manufacture of the Cathode Implanter on the Distribution of Implantable Ions in the Surface Layer of Steel 30ХГCH2A.// High Technology in Mechanical Engineering, 2013. No.2. -P. 3-8.

[23] Ovchinnikov V. V., Borodin Y. M., Luk'yanenko, E. V., Lishchuk S A. Wear Resistance of Parts Made of Steel 30XГCH2A Subjected to
Ion Implantation After Ultrasonic Processing. // Blank Productions in Mechanical Engineering. 2014. No.9. - P. 40-44.

[24] Ovchinnikov V. V., Borodin Y. M., Luk'yanenko, E. V., Yarnykh, A. A. Improvement of Wear Resistance of Steel 30XГCH2A by Implantation of Nitrogen Ions and Metals Ions. // Materials Science. 2014. No. 11. P. $30-35$.

[25] Yarnykh, A. A., Borodin Y. M., Ovchinnikov V. V., Makeev, Yu. A. Study of the Multielemental Ion Implantation features Using Composite Cathodes Copper-Lead. //Metal Technology. 2014. No.12. - p 29-35.

[26] Kostrjitskiy A. I., T. V. Cheban, R. A. Podolyan, Oxide Films on Iron Surface and their Physical and Chemical Properties. // Electronic Processing of Materials. - 2007. - No. 3. - p. 50-55.

[27] Belov M. I., Ovchinnikov V. V., Lukyanenko E. V., Yakutina S.V. Modeling of the Distribution of Ion-Implanted Atoms in the Meta Targets. // Electrometallurgy. 2016. - No. 11. - p. 31-41.

[28] Ovchinnikov V.V., Borovin Yu.M. Ion Implantation of Surface Layers of Machine Parts. // High Technologies in Mechanical Engineering. 2010. - No.6. - P. 29-39.

[29] This article has been made within the framework of the government order No.11.3560.2017/PCh. 